\title{
Transcatheter tricuspid valve repair: early experience in the Netherlands
}

\author{
F. Meijerink · K. T. Koch · R. J. de Winter · M. Holierook - B. J. W. M. Rensing • L. Timmers · F. D. Eefting \\ M. J. Swaans · B. J. Bouma · J. Baan
}

Accepted: 6 July 2021 / Published online: 20 August 2021

(c) The Author(s) 2021

\begin{abstract}
Background Symptomatic tricuspid regurgitation (TR) is increasingly prevalent and impairs quality of life and survival, despite medical treatment. Transcatheter tricuspid valve repair (TTVR) has recently become available as a treatment option for patients not eligible for tricuspid valve surgery. In this study we describe the early experience with TTVR in the Netherlands.

Methods All consecutive patients scheduled for TTVR in two tertiary hospitals were included in the current study. Patients were symptomatic and had severe functional TR. TTVR was performed either with the MitraClip (off-label use) or dedicated TriClip delivery system and device. Procedural success was defined as achievement of clip implantation, TR reduction $\geq 1$ grade and no need for re-do surgical or transcatheter intervention. Clinical improvement was evaluated after 4 weeks.

Results Twenty-one patients (median age 78 years, $33 \%$ male, 95\% New York Heart Association class $\geq 3$, $100 \%$ history of atrial fibrillation) underwent TTVR. Procedural success was achieved in 16 patients, of whom 15 reported symptomatic improvement (New
\end{abstract}

B.J. Bouma and J. Baan share senior authorship.

Supplementary Information The online version of this article (https://doi.org/10.1007/s12471-021-01613-3) contains supplementary material, which is available to authorized users.

F. Meijerink · K. T. Koch · R. J. de Winter · M. Holierook ·

B. J. Bouma · J. Baan $(\varangle)$

Department of Cardiology, Amsterdam UMC, location AMC,

Amsterdam, The Netherlands

j.baan@amsterdamumc.nl

B. J. W. M. Rensing · L. Timmers · F. D. Eefting · M. J. Swaans Department of Cardiology, St Antonius Hospital,

Nieuwegein, The Netherlands
York Heart Association class 1 or 2). There was no in-hospital mortality and no major complications occurred. Baseline glomerular filtration rate and TR coaptation gap size were associated with procedural success.

Conclusion The current study showed that TTVR seems a promising treatment option for patients with severe functional TR deemed high risk for surgery. Successful TR reduction is most likely in patients with limited coaptation gap size and strongly determines clinical benefit. Adequate patient selection and timing of treatment seem essential for an optimal patient outcome.

Keywords Tricuspid regurgitation - Transcatheter treatment · Valvular heart disease · Echocardiography

\section{What's new?}

- Transcatheter tricuspid valve repair (TTVR) is now available for patients with symptomatic tricuspid regurgitation (TR) not eligible for valve surgery.

- When TR reduction $\geq 1$ grade can be established, clinical improvement is likely.

- Coaptation gap size is the most important determinant of a successful procedure.

- Patients with no significant left-sided heart valve disease, preserved right ventricular function, no pulmonary hypertension and a coaptation gap size $<10 \mathrm{~mm}$ should be considered for TTVR. 
Fig. 1 a Tricuspid valve (TV) anatomy and most common clip locations (grey dots). Three-dimensional echocardiographic view of the TV $\mathbf{b}$ before and $\mathbf{c}$ after implantation of two clips on the anterior and septal leaflets. $A$ anterior leaflet, $P$ posterior leaflet, $S$ septal leaflet

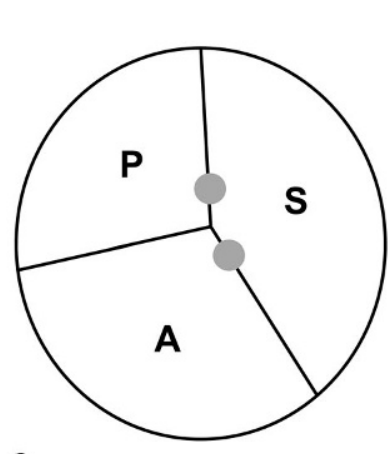

a
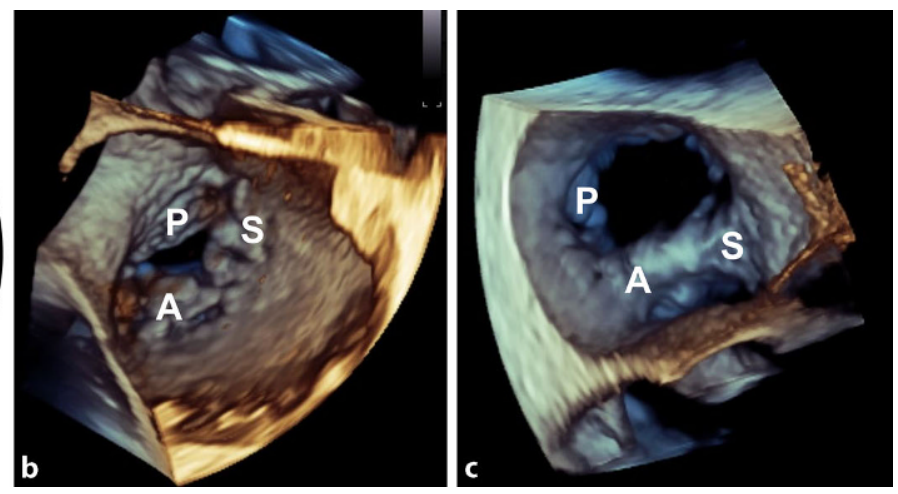

\section{Introduction}

Tricuspid regurgitation (TR) is as common as mitral regurgitation (MR) in the general population and its prevalence increases with age. Functional TR accounts for up to $90 \%$ of patients. Annular dilatation and increased tricuspid leaflet tethering in relation to right ventricular (RV) pressure and/or volume overload cause functional TR. Left-sided heart disease, atrial fibrillation (AF) or pulmonary hypertension are frequently involved in the pathogenesis of TR $[1,2]$. Significant TR often leads to right-sided heart failure symptoms and is associated with increased morbidity and mortality [3]. Once TR is present, a vicious circle arises where TR begets more RV and right atrial (RA) dilatation, leading to more TR. Whilst tricuspid valve (TV) intervention is indicated when symptomatic TR is present, the risk of surgery is deemed to be too high in most patients with isolated TR due to the presence of RV dysfunction, advanced age or other (cardiac) co-morbidities [4]. Until recently, these patients could only be treated with medical therapy, but transcatheter tricuspid valve repair (TTVR) is now available. The aim of this study was to evaluate the early experience with TTVR in the Netherlands with a focus on patient selection, safety and effectiveness of the procedure as well as determinants of procedural success.

\section{Methods}

\section{Study population}

All consecutive patients who underwent TTVR at Amsterdam University Medical Centre, location AMC, Amsterdam and St Antonius Hospital, Nieuwegein between October 2019 and February 2021 were included. Patients were admitted via the heart team and screened by a dedicated transcatheter valve intervention team. In all patients, the risk of TV surgery was deemed to be too high. All patients consented to participation and the study was conducted in accordance with the Declaration of Helsinki.

\section{Echocardiography}

TR severity was determined by transthoracic echocardiography (TTE) and graded according to the latest classification, including massive and torrential TR [5]. These additional grades are highly relevant, because patients often present with TR largely exceeding the guideline cutoff criteria for severe TR. Reduction to less than severe TR is not always achieved, but has appeared to be associated with improved outcome. Standard parameters were included according to the guidelines of the American Society for Echocardiography (ASE) and European Association of Cardiovascular Imaging (EACVI) [6, 7].

\section{Procedure}

TTVR was performed using the clip-based edge-toedge technique with the MitraClip device (Abbott, Santa Clara, CA, USA) as off-label use in 13 patients. The dedicated TriClip device (Abbott) has been available for clinical use in the Netherlands since September 2020 and was used in 8 patients [8]. Major improvements offered by the TriClip device include (1) extended flexion of the guiding catheter, which provides improved height adjustment above the valve and (2) improved motion in septal and lateral directions, which increases the reach when placing clips in the antero-septal (AS) and postero-septal (PS) commissures, allowing more complex jets to be treated. Figure S1 (see Electronic Supplementary Material) shows both systems and the specific differences. After obtaining access to the femoral vein, the guiding catheter was introduced. The clip delivery system was subsequently inserted into the guiding catheter and positioned above the TV. The principle of the edge-toedge technique is to grasp two leaflets with the clip, closing and deploying the device and thereby creating two or more orifices [9]. The grasp was targeted at either the AS, PS or antero-posterior leaflets (Fig. 1). If TR reduction was not sufficient after implantation of one clip, additional clips were implanted, depending on the TV gradient. The procedures were done with the patient under general anaesthesia, guided by three-dimensional transoesophageal echocardio- 
Table 1 Anatomical and functional criteria for transcatheter tricuspid edge-to-edge repair (adapted from Hausleiter et al. [10], including number of patients)

\begin{tabular}{|c|c|c|c|c|c|c|}
\hline & Most appropriate & $n$ & Possibly appropriate & $n$ & Least appropriate & $n$ \\
\hline Leaflet appearance & Normal & 20 & $\begin{array}{l}\text { Primary TR with prolapse } \\
\text { (width }<12 \mathrm{~mm} \text { ) }\end{array}$ & 0 & $\begin{array}{l}\text { Thickening, shortening, destruction or large prolapse } \\
(>12 \mathrm{~mm})\end{array}$ & 1 \\
\hline Coaptation gap & $<4 \mathrm{~mm}$ & 6 & $4-7 \mathrm{~mm}$ & 3 & $>7 \mathrm{~mm}$ & 12 \\
\hline Jet location & $\begin{array}{l}\text { Central } \\
\text { AS commissure }\end{array}$ & 20 & $\begin{array}{l}\text { Central } \\
\text { PS commissure }\end{array}$ & 0 & $\begin{array}{l}\text { Non-central } \\
\text { AP commissure }\end{array}$ & 1 \\
\hline Leaflet visualisation (echo) & Good & 17 & Sufficient & 4 & Insufficient & 0 \\
\hline PM/ICD lead & No & 21 & $\begin{array}{l}\text { Present } \\
\text { No interaction }\end{array}$ & 0 & Lead-induced TR & 0 \\
\hline RV function & Normal & 10 & Moderately reduced & 10 & Severely reduced & 1 \\
\hline Systolic PAP & Normal & 16 & $40-60 \mathrm{~mm} \mathrm{Hg}$ & 5 & $>60 \mathrm{~mm} \mathrm{Hg}$ & 0 \\
\hline
\end{tabular}

$A P$ antero-posterior, $A S$ antero-septal, $I C D$ implantable cardioverter defibrillator, $P A P$ pulmonary artery pressure, $P M$ pacemaker, $P S$ postero-septal, $R V$ right ventricle, $T R$ tricuspid regurgitation

graphy (TEE) and fluoroscopy. The treatment team consisted of one imaging cardiologist and two interventional cardiologists, who together determined the clip strategy.

\section{Data and outcome}

Baseline clinical and echocardiographic data were collected. Clinical follow-up was conducted after 4 weeks. Technical success was achieved when the clip could be implanted and procedural success was defined as a successful clip implantation, TR reduction $\geq 1$ grade and no need for additional surgical or transcatheter TV intervention at follow-up. Procedural and in-hospital complications were recorded. Comparisons were made between patients that underwent successful and non-successful procedures.

Retrospective stratification of eligibility for tricuspid edge-to-edge repair was performed for each patient according to anatomical and functional criteria (Tab. 1; [10]).

\section{Statistical analysis}

Categorical variables are expressed as $n(\%)$ and were compared using the chi-squared or Fisher's exact test. Continuous variables are expressed as median and range (minimum to maximum) and were compared using the Mann-Whitney $U$ test. Statistical significance was established at $p<0.05$. All analyses were done using SPSS version 26 (IBM, Armonk, NY, USA).

\section{Results}

\section{Study population}

Twenty-one patients underwent TTVR. Clinical data of all patients are presented in Tab. 2. Twenty patients (95\%) were in New York Heart Association (NYHA) class 3 or 4 . Most common symptoms were dyspnoea $(95 \%)$, peripheral oedema $(62 \%)$ and ascites (19\%); 13 patients $(62 \%)$ had recently been hospitalised for heart failure. All patients were on optimal doses of medical therapy for heart failure: $91 \%$ loop diuretic, $76 \%$ beta-blocker, $57 \%$ aldosterone antagonist, 38\% angiotensin converting enzyme inhibitor/ angiotensin II antagonist. All patients had functional TR (38\% severe, $43 \%$ massive, $19 \%$ torrential).

\section{Procedural characteristics, complications and outcome}

In Tab. 3 procedural and outcome data are shown. Technical success was achieved in 18 patients $(86 \%)$ and TR could be reduced ( $\geq 1$ grade) in 17 patients (81\%). No in-hospital mortality occurred. Five patients experienced a femoral access-site bleeding, which could be conservatively managed with a pressure bandage in 4 patients. In 1 patient the femoral vein was inadvertently punctured, resulting in a lesion of the femoral vein after introduction of the guiding catheter. Surgical exploration including femoral vein repair was needed after the procedure.

None of the patients experienced myocardial infarction, renal failure, pulmonary embolism, device thrombosis, new liver failure, tricuspid stenosis or clip embolisation. Single leaflet clip detachment occurred in 2 patients and resulted in persistent severe TR. Both needed additional intervention (1 surgical TV replacement and 1 re-do TTVR). Procedural success was achieved in 16 patients (76\%), of whom 15 reported improvement of symptoms (NYHA 1 or 2). In those who did not achieve procedural success $(n=5)$, re-do TTVR was performed in 1, TV surgery in 2 and no additional treatment was performed in 2 patients, both of who had an absolute contraindication for surgery. Two patients died ( 6 and 8 weeks after the procedure, respectively) due to pre-existent and irreversible RV failure. In 1 of these patients a clip could not be implanted during the procedure.

In patients that underwent a successful procedure, median glomerular filtration rate $\left(\mathrm{ml} / \mathrm{min}\right.$ per $\left.1.73 \mathrm{~m}^{2}\right)$ was lower (77 vs $51, p=0.04$ ) and TR coaptation gap size $(\mathrm{mm})$ was smaller ( 14 vs. $7, p=0.01)$. Median systolic pulmonary artery pressure (PAP) $(\mathrm{mm} \mathrm{Hg})$ was lower in patients with procedural success (44 vs. 31, 
Table 2 Baseline characteristics

\begin{tabular}{|c|c|c|c|c|}
\hline Variable & $\begin{array}{l}\text { All patients } \\
(n=21)\end{array}$ & $\begin{array}{l}\text { Procedural } \\
\text { success } \\
(n=16)\end{array}$ & $\begin{array}{l}\text { No procedural } \\
\text { success } \\
(n=5)\end{array}$ & $p$-value \\
\hline \multicolumn{5}{|l|}{ Clinical } \\
\hline Age (years) & $78(60-87)$ & $79(60-87)$ & $76(60-84)$ & 0.36 \\
\hline Male (\%) & $7(33)$ & $5(31)$ & $2(40)$ & 1.00 \\
\hline BMI $\left(\mathrm{kg} / \mathrm{m}^{2}\right)$ & $\begin{array}{l}24.9 \\
(18.4-36.1)\end{array}$ & $\begin{array}{l}24.5 \\
(20.2-36.1)\end{array}$ & $\begin{array}{l}25.1 \\
(18.4-27.1)\end{array}$ & 0.80 \\
\hline COPD (\%) & $1(5)$ & $0(0)$ & $1(20)$ & 0.24 \\
\hline $\begin{array}{l}\text { Peripheral arterial } \\
\text { disease (\%) }\end{array}$ & $0(0)$ & $0(0)$ & $0(0)$ & - \\
\hline Stroke & $4(19)$ & $4(25)$ & $0(0)$ & 0.53 \\
\hline Diabetes mellitus & $4(19)$ & $2(13)$ & $2(40)$ & 0.23 \\
\hline Atrial fibrillation & $21(100)$ & $16(100)$ & $5(100)$ & - \\
\hline $\begin{array}{l}\text { Myocardial infarc- } \\
\text { tion }\end{array}$ & $1(5)$ & $0(0)$ & $1(20)$ & 0.24 \\
\hline Pacemaker/ICD & $0(0)$ & $0(0)$ & $0(0)$ & - \\
\hline \multicolumn{4}{|c|}{ Previous cardiac surgery } & 0.74 \\
\hline CABG & $1(5)$ & $1(6)$ & $0(0)$ & \\
\hline AVR & $2(10)$ & $2(13)$ & $0(0)$ & \\
\hline MVR & $2(10)$ & $1(6)$ & $1(20)$ & \\
\hline Pericardectomy & $2(10)$ & $1(6)$ & $1(20)$ & \\
\hline ASD closure & $1(5)$ & $1(6)$ & $0(0)$ & \\
\hline $\begin{array}{l}\text { GFR }(\mathrm{ml} / \mathrm{min} \text { per } \\
\left.1.73 \mathrm{~m}^{2}\right)\end{array}$ & $58(13-83)$ & $51(13-80)$ & $77(53-83)$ & 0.04 \\
\hline \multicolumn{4}{|l|}{ NYHA class } & 0.85 \\
\hline 2 & $1(5)$ & 1 (6) & $0(0)$ & \\
\hline 3 & $16(76)$ & $12(75)$ & $4(80)$ & \\
\hline 4 & $4(19)$ & $3(19)$ & $1(20)$ & \\
\hline \multicolumn{5}{|l|}{ Echo } \\
\hline LVEF (\%) & $50(32-71)$ & $50(40-71)$ & $50(32-54)$ & 0.32 \\
\hline LVEDV (ml) & $72(44-180)$ & $68(44-180)$ & $78(52-90)$ & 0.36 \\
\hline LVESV (ml) & 35 (20-95) & $33(20-95)$ & $44(25-60)$ & 0.25 \\
\hline LA volume (ml) & 81 (37-271) & $80(37-271)$ & $100(72-195)$ & 0.40 \\
\hline RA volume (ml) & $134(70-678)$ & $123(70-273)$ & $187(70-678)$ & 0.22 \\
\hline TAPSE (mm) & $13(8-26)$ & $13(8-26)$ & $16(11-22)$ & 0.46 \\
\hline RV S' (cm/s) & $8(5-15)$ & $8(5-15)$ & $9(7-10)$ & 0.78 \\
\hline $\begin{array}{l}\text { Systolic PAP } \\
(\mathrm{mm} \mathrm{Hg})\end{array}$ & $35(20-51)$ & $31(20-42)$ & $44(35-51)$ & 0.06 \\
\hline $\begin{array}{l}\mathrm{MR} \geq \text { moderate } \\
(\%)\end{array}$ & $6(29)$ & $5(31)$ & $1(20)$ & 1.00 \\
\hline AS (\%) & 1 (5) & $0(0)$ & $1(20)$ & 0.24 \\
\hline
\end{tabular}

$p=0.06)$, although this difference was not significant. Coaptation gap size was $<10 \mathrm{~mm}$ in 14 patients $(93 \%$ procedural success) and $>10 \mathrm{~mm}$ in 7 patients $(43 \%$ procedural success). The largest coaptation gap in patients that achieved procedural success was $13 \mathrm{~mm}$.

\section{Stratification of eligibility}

Tab. 1 shows seven parameters and the number of patients in each category of eligibility for TTVR. One patient with septal leaflet destruction and a large prolapse gap was classified as least eligible. Initially the patient had a massive functional TR with possible in-
Table 2 (Continued)

\begin{tabular}{|c|c|c|c|c|}
\hline Variable & $\begin{array}{l}\text { All patients } \\
(n=21)\end{array}$ & $\begin{array}{l}\text { Procedural } \\
\text { success } \\
(n=16)\end{array}$ & $\begin{array}{l}\text { No procedural } \\
\text { success } \\
(n=5)\end{array}$ & $p$-value \\
\hline TR grade & & & & 0.43 \\
\hline 3 (severe) & $8(38)$ & $6(38)$ & $2(40)$ & \\
\hline 4 (massive) & $9(43)$ & $6(38)$ & $3(60)$ & \\
\hline 5 (torrential) & $4(19)$ & $4(25)$ & $0(0)$ & \\
\hline $\begin{array}{l}\text { TR vena contracta } \\
(\mathrm{mm})\end{array}$ & $14(2-25)$ & $14(2-25)$ & $13(8-19)$ & 0.90 \\
\hline $\begin{array}{l}\text { TR coaptation gap } \\
(\mathrm{mm})\end{array}$ & $8(1-20)$ & $7(1-13)$ & $14(7-20)$ & 0.01 \\
\hline Functional TR & $21(100)$ & $16(100)$ & $5(100)$ & - \\
\hline $\begin{array}{l}\text { Annulus diameter } \\
(\mathrm{mm})\end{array}$ & $48(35-68)$ & $47(35-56)$ & $50(40-68)$ & 0.56 \\
\hline
\end{tabular}

Continuous variables are expressed as median (range). For categorical variables number (\%) are shown

$A S$ aortic valve stenosis, $A S D$ atrial septal defect, $A V R$ aortic valve replacement, $B M /$ body mass index, $C A B G$ coronary artery bypass grafting, COPD chronic obstructive pulmonary disease, GFR glomerular filtration rate, ICD implantable cardioverter defibrillator, LA left atrium, LVEDV left ventricular end-diastolic volume, LVESV left ventricular end-systolic volume, LVEF left ventricular ejection fraction, $M R$ mitral regurgitation, $M V R$ mitral valve repair/replacement, NYHA New York Heart Association, PAP pulmonary artery pressure, $R A$ right atrium, $R V S^{\prime}$ right ventricular systolic myocardial velocity, TAPSE tricuspid annular plane systolic excursion, TR tricuspid regurgitation

terference of a pacemaker lead. To qualify for TTVR, the lead was extracted and replaced with a leadless pacemaker. During the procedure a large prolapse segment and a short septal leaflet were seen, probably due to leaflet destruction caused by lead extraction. Twelve patients with a coaptation gap $>7 \mathrm{~mm}$ qualified as least eligible, 8 of whom still achieved procedural success. RV function was moderately reduced in 10 patients (qualifying as possibly eligible) and severely reduced in 1 (qualifying as least eligible). Sixteen patients had normal systolic PAP (qualifying as most eligible).

\section{Discussion}

In this study the early experience and results of TTVR in the Netherlands are reported. Our findings demonstrate that TTVR is safe and that TR can be reduced in most patients. A successful procedure led to improvement of symptoms in $>90 \%$ of patients.

Procedural success ( $76 \%$ in the current study) has shown to be the main determinant of survival and clinical benefit after TTVR $[11,12]$. It is important to note that moderate or severe TR often persists after a successful procedure. However the current and earlier studies confirmed that if TR could be reduced by 1 grade, clinical benefit was likely [9]. This suggests that severe, massive and torrential TR have a significant impact on clinical status, which might strongly improve after TTVR, even when only a mild reduction can be achieved. Whether this will translate to reduction of heart failure hospitalisations and better survival has yet to be confirmed. Coaptation gap size was the most relevant determinant of successful 


\section{Advertisement placed here.}

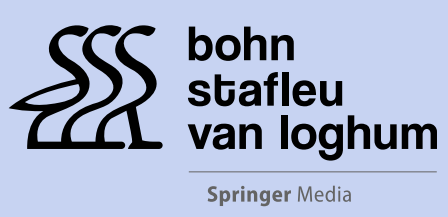

Houten 2021 


\section{Advertisement placed here.}

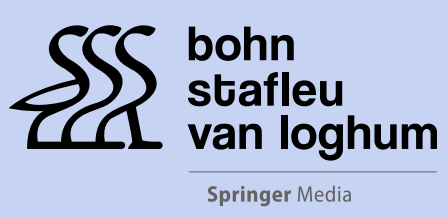

Houten 2021 
Table 3 Procedural characteristics and outcome in hospital and at follow-up

\begin{tabular}{|c|c|c|c|c|}
\hline Variable & $\begin{array}{l}\text { All pa- } \\
\text { tients } \\
(n=21)\end{array}$ & $\begin{array}{l}\text { Procedura } \\
\text { success } \\
(n=16)\end{array}$ & $\begin{array}{l}\text { No pro- } \\
\text { cedural } \\
\text { success } \\
(n=5)\end{array}$ & $p$-value \\
\hline \multicolumn{5}{|l|}{ Procedural } \\
\hline Delivery system & & & & 1.00 \\
\hline MitraClip & $13(62)$ & $10(63)$ & $3(60)$ & \\
\hline TriClip & $8(38)$ & $6(37)$ & $2(40)$ & \\
\hline Technical success & $18(86)$ & $16(100)$ & $2(40)$ & 0.008 \\
\hline TR reduction $\geq 1$ grade & $17(81)$ & $16(100)$ & $1(20)$ & 0.001 \\
\hline TV mean gradient $(\mathrm{mm} \mathrm{Hg})$ & $2(1-5)$ & $2(1-5)$ & $3(3-3)$ & 0.13 \\
\hline Number of clips & $2(0-4)$ & $2(1-4)$ & $0(0-3)$ & 0.17 \\
\hline Clip location (leaflets) & & & & 0.32 \\
\hline Antero-septal & $9(43)$ & $9(56)$ & $2(40)$ & \\
\hline Antero-septal/Postero-septal & $7(33)$ & $5(31)$ & $0(0)$ & \\
\hline Antero-septal/Antero-posterior & 1 (5) & $1(6)$ & $0(0)$ & \\
\hline Postero-septal & $1(5)$ & $1(6)$ & $0(0)$ & \\
\hline \multicolumn{5}{|l|}{ Safety } \\
\hline Death & $2(10)$ & $1(6)$ & $1(20)$ & 0.43 \\
\hline Femoral access-site bleeding & $5(24)$ & $4(25)$ & $1(20)$ & 1.00 \\
\hline Single leaflet detachment & $2(10)$ & $0(0)$ & $2(40)$ & 0.05 \\
\hline \multicolumn{5}{|l|}{ Outcome } \\
\hline TR reduction & & & & $<0.001$ \\
\hline$\geq 2$ grades & $10(48)$ & $10(63)$ & $0(0)$ & \\
\hline 1 grade & $7(33)$ & $6(38)$ & $1(20)$ & \\
\hline No reduction & $4(19)$ & $0(0)$ & $4(80)$ & \\
\hline $\begin{array}{l}\text { TR grade } \leq \text { moderate at dis- } \\
\text { charge }\end{array}$ & $12(57)$ & $12(75)$ & $0(0)$ & 0.006 \\
\hline NYHA class 1 or 2 at follow-up & $15(71)$ & $15(94)$ & $0(0)$ & 0.001 \\
\hline $\begin{array}{l}\text { Surgical or percutaneous re- } \\
\text { do procedure }\end{array}$ & $3(14)$ & $0(0)$ & $3(60)$ & 0.008 \\
\hline \multicolumn{5}{|c|}{$\begin{array}{l}\text { Continuous variables are expressed as median (range). For categorical vari- } \\
\text { ables number (\%) are shown } \\
\text { NYHA New York Heart Association, } T R \text { tricuspid regurgitation, } T V \text { tricuspid } \\
\text { valve }\end{array}$} \\
\hline
\end{tabular}

reduction in the current study. Earlier studies also mentioned leaflet tenting area $\left(>3.15 \mathrm{~cm}^{2}\right)$, coaptation depth $(>9.75 \mathrm{~mm})$ and effective regurgitant orifice area $\left(>69.5 \mathrm{~mm}^{2}\right)$ as determinants [13]. These echocardiographic parameters should play an important role in patient selection.

Currently, no established guideline exists for TTVR and so indication for treatment is made at the patient level by a dedicated transcatheter valve intervention team. Recommendations for TTVR appropriateness, according to clinical and anatomical factors, have been made previously (Tab. 1; [10]). For successful clip implantation it is essential that adequate leaflet grasping can be performed, where the tips of two leaflets can be inserted completely into the clip device. Improved coaptation (reducing TR) and successful clip implantation (preventing single leaflet detachment) are hereby achieved. Structurally nonnormal leaflets or inadequate visualisation might prevent successful leaflet grasping. Adequate TEE imag- ing windows of the TV are therefore highly relevant, though sometimes difficult to obtain. If a PM lead is not interfering with the leaflets, it is not a contra-indication. Recurrent TR after repair is likely in patients with severely reduced RV function and pulmonary hypertension (systolic PAP $>60 \mathrm{~mm} \mathrm{Hg}$ ). TTVR is therefore not recommended in such patients [10].

After stratifying each patient for all factors, we observed that leaflet appearance and jet location were highly appropriate for TTVR in most patients ( $\geq 95 \%)$ and that none had a pacemaker or implantable cardioverter defibrillator lead during the procedure. The coaptation gap was $>7 \mathrm{~mm}$ in 12 patients, which would classify them as 'least eligible' according to the recommendation. However, we observed that procedural success and clinical improvement were still achieved in 8 patients with a gap size $>7 \mathrm{~mm}$ (largest $13 \mathrm{~mm})$. It should be noted that only large clip devices (XTR, arm length $12 \mathrm{~mm}$ ) were used, which likely explains the improved results in patients with large coaptation gaps. The recommendations by Hausleiter et al. are based on earlier experience when only small clips (NTR, arm length $9 \mathrm{~mm}$ ) were used [14]. A recent study confirmed that patients with large coaptation gaps could be effectively treated with the XTR clip [15]. Thus, whilst TTVR is more likely to succeed when the coaptation gap is smaller, in our experience treatment was feasible with a defect of up to $10 \mathrm{~mm}$, with a success rate of $93 \%$. Three patients with a defect between 10 and $13 \mathrm{~mm}$ could still be effectively treated, although earlier studies report decreased success in this range [16]. RV function was classified as 'possibly' or 'least' appropriate' in 9 patients. This did not affect procedural success, though it might affect the clinical benefit of the procedure. A recommendation for patients that could be considered for TTVR is presented in Fig. 2.

Timing of treatment for TR can be challenging. TV repair is recommended when severe TR is symptomatic or when progressive RV dysfunction is present [4]. However, once patients become symptomatic, there are often irreversible signs of right-sided heart failure and TR severity is beyond the guideline cutoff (massive or torrential). Advanced RV dilatation further distorts the TV anatomy (causing excessive leaflet tenting and a large coaptation gap) and impairs the clinical benefit after TTVR. Ideally, TTVR should be performed when the valve anatomy is not yet distorted by the disease itself and RV function is preserved. Careful diagnosis and patient evaluation, by using multi-parametric and quantitative approaches to assess TR and RV function, are therefore essential. Also, these should not be evaluated in one snapshot because varying volume status, blood pressure and heart rhythm have a great impact on assessment of the severity of TR and RV function.

As with transcatheter mitral valve repair (TMVR), complications after TTVR are rare. Single leaflet clip detachment occurred in 2 patients and prevented ad- 


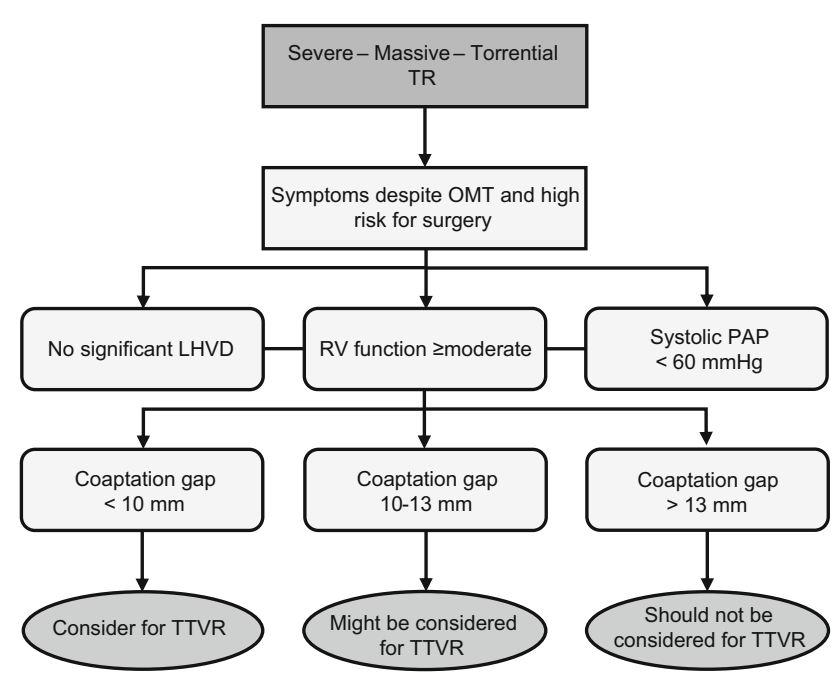

Fig. 2 Recommendation of patients that should be referred and considered for transcatheter tricuspid valve repair (TTVR). LHVD left-sided heart valve disease, OMT optimal medical therapy, $P A P$ pulmonary artery pressure, $R V$ right ventricle, $T R$ tricuspid regurgitation

equate TR reduction. It is therefore an important determinant of procedural success [9]. We did not observe TV stenosis after TTVR. Currently, a mean gradient $\leq 3 \mathrm{~mm} \mathrm{Hg}$ is considered clinically acceptable [9]. A clip strategy targeted at the AS and PS leaflets warrants sufficient valve orifice area and was performed in most patients. Since tricuspid annulus dilatation is most pronounced in the anterior and posterior region, the anterior and posterior leaflets tend to become separated from the septal leaflet. Clips on both AS and PS leaflets improve coaptation and might prevent further leaflet separation [10]. Femoral access-site bleeding was seen in 5 patients and could be conservatively managed in 4. Minor access-site bleeding occurs in $5-10 \%$ of patients undergoing TMVR [17]. Haemostasis is usually achieved after removal of the guiding catheter and administration of protamine (to reverse the effect of heparin), skin closure with a figure-ofeight suture and subsequent application of a pneumatic compression device for $6 \mathrm{~h}$. Oral anticoagulation should be started $\geq 24 \mathrm{~h}$ after the procedure. Access-site closure with ProGlide (Abbott) devices is an effective method as well [18].

\section{Future perspectives}

TR reduction and procedural success might be further optimised by an improved (wider) clip device and delivery system allowing for independent leaflet grasping, which is expected shortly. Alternative devices might be useful for patients with large coaptation defects and extensive RV or tricuspid annulus dilatation. The positive results of TTVR pose the question as to whether a combined transcatheter MV and TV procedure could be beneficial for patients with MR and concomitant TR. Early studies showed that combined
TMVR and TTVR were associated with improved clinical outcome and survival compared to TMVR alone in these patients $[19,20]$. However, one could argue that the effect of TMVR on clinical status and TR should be awaited before considering TTVR.

The findings of the current study warrant further randomised studies and prospective registries to confirm the safety and effectiveness of TTVR. Ideally, such studies should include echocardiography core laboratory analysis and adequate functional assessment (exercise testing, cardiac magnetic resonance imaging) of TR and RV function before and after TTVR.

\section{Clinical implications}

TR is a complex condition and TTVR could be an effective treatment for selected patients. The current study showed encouraging results that will hopefully translate into long-term benefit as well. One-year follow-up of the TriValve registry showed a significant decrease in hospitalisations for heart failure and improvement of symptoms, exercise capacity and quality of life. Interestingly, RV reverse remodelling was also observed $[8,21]$.

Procedural success has shown to be the major determinant of clinical outcome, which indicates that adequate patient selection focusing on clinical and anatomical aspects is crucial. Patients at an advanced stage of TR and RV disease might benefit less from TTVR and have a higher risk of procedural failure when a large coaptation gap is present. Timely diagnosis and treatment could therefore strongly improve outcome.

\section{Limitations}

No independent echocardiographic data analysis was done in the current study. All echocardiographic measurements were performed by an experienced investigator (FM) and reviewed by an imaging cardiologist (BB) in accordance with the ASE and EACVI guidelines $[6,7]$.

\section{Conclusion}

TTVR seems to be a promising treatment option for patients with severe functional TR deemed high risk for surgery. Successful TR reduction is most likely in patients with limited coaptation gap size and strongly determines clinical benefit. Adequate patient selection and timing of treatment seem essential for an optimal patient outcome.

Conflict of interest J. Baan receives an unrestricted research grant from Abbott Vascular. M.J. Swaans is a consultant for Abbott Vascular. F. Meijerink, K.T. Koch, R.J. de Winter, M. Holierook,B.J.W.M. Rensing, L. Timmers, F.D. Eefting and B.J. Bouma declare that they have no competing interests. 
Open Access This article is licensed under a Creative Commons Attribution 4.0 International License, which permits use, sharing, adaptation, distribution and reproduction in any medium or format, as long as you give appropriate credit to the original author(s) and the source, provide a link to the Creative Commons licence, and indicate if changes were made. The images or other third party material in this article are included in the article's Creative Commons licence, unless indicated otherwise in a credit line to the material. If material is not included in the article's Creative Commons licence and your intended use is not permitted by statutory regulation or exceeds the permitted use, you will need to obtain permission directly from the copyright holder. To view a copy of this licence, visit http://creativecommons.org/licenses/by/4.0/.

\section{References}

1. Rodes-Cabau J, Taramasso M, O'Gara PT. Diagnosis and treatment of tricuspid valve disease: current and future perspectives. Lancet. 2016;388:2431-42.

2. Fender EA, Zack CJ, Nishimura RA. Isolated tricuspid regurgitation: outcomes and therapeutic interventions. Heart. 2018;104:798-806.

3. Topilsky Y, Maltais S, Medina Inojosa J, et al. Burden of tricuspid regurgitation in patients diagnosed in the community setting. JACC Cardiovasc Imaging. 2019;12:433-42.

4. Baumgartner H, Falk V, Bax JJ, et al. 2017 ESC/EACTS guidelines for the management of valvular heart disease. Eur Heart J. 2017;38:2739-91.

5. Hahn RT, Zamorano JL. The need for a new tricuspid regurgitation grading scheme. Eur Heart J Cardiovasc Imaging. 2017;18:1342-3.

6. Lancellotti P, Tribouilloy C, HagendorffA, et al. Recommendations for the echocardiographic assessment of native valvular regurgitation: an executive summary from the European Association of Cardiovascular Imaging. Eur Heart J Cardiovasc Imaging. 2013;14:611-44.

7. Zoghbi WA, Adams D, Bonow RO, et al. Recommendations for noninvasive evaluation of native valvular regurgitation: a report from the American Society of Echocardiography. Developed in collaboration with the Society for Cardiovascular Magnetic Resonance. J Am Soc Echocardiogr. 2017;30:303-71.

8. Nickenig G, Weber M, Lurz P, et al. Transcatheter edgeto-edge repair for reduction of tricuspid regurgitation: 6-month outcomes of the TRILUMINATE single-arm study. Lancet. 2019;394:2002-11.

9. Nickenig G, Kowalski M, Hausleiter J, et al. Transcatheter treatment of severe tricuspid regurgitation with the edge-to-edge Mitraclip technique. Circulation. 2017;135:1802-14.

10. Hausleiter J, Braun D, Orban M, et al. Patient selection, echocardiographic screening and treatment strategies for interventional tricuspid repair using the edge-to-edge repair technique. EuroIntervention. 2018;14:645-53.

11. Taramasso M, Alessandrini H, Latib A, et al. Outcomes after current transcatheter tricuspid valve intervention: midterm results from the International TriValve Registry. JACC Cardiovasc Interv. 2019;12:155-65.

12. Mehr M, Taramasso M, Besler C, et al. 1-Year outcomes after edge-to-edge valve repair for symptomatic tricuspid regurgitation: results from the TriValve Registry. JACC Cardiovasc Interv. 2019;12:1451-61.

13. Orban M, Rommel KP, Ho EC, et al. Transcatheter edgeto-edge tricuspid repair for severe tricuspid regurgitation reduces hospitalizations for heart failure. JACC Heart Fail. 2020;8:265-76.

14. Besler C, Orban M, Rommel KP, et al. Predictors of procedural and clinical outcomes in patients with symptomatic tricuspid regurgitation undergoing transcatheter edge-toedge repair. JACC Cardiovasc Interv. 2018;11:1119-28.

15. AliFM, Ong G, Edwards J, Connelly KA, Fam NP.Comparison of transcatheter tricuspid valve repair using the MitraClip NTR andXTR systems. Int J Cardiol. 2021;327:156-62.

16. Braun D, Rommel KP, Orban M, et al. Acute and shortterm results of transcatheter edge-to-edge repair for severe tricuspid regurgitation using the MitraClip XTR system. JACC Cardiovasc Interv. 2019;12:604-5.

17. Paukovitsch M, Schepperle N, Pott A, et al. Impact of bleeding complications after transcatheter mitral valve repair. Int J Cardiol Heart Vasc. 2021;32:100707.

18. Steppich B, Stegmuller F, Rumpf PM, et al. Vascular complications after percutaneous mitral valve repair and venous access closure using suture or closure device. J Interv Cardiol. 2018;31:223-9.

19. Besler C, Blazek S, Rommel KP, et al. Combined mitral and tricuspid versus isolated mitral valve transcatheter edge-to-edge repair in patients with symptomatic valve regurgitation at high surgical risk. JACC Cardiovasc Interv. 2018;11:1142-51.

20. Mehr M, Karam N, Taramasso M, et al. Combined tricuspid and mitral versus isolated mitral valve repair for severe MR and TR: an analysis from the TriValve and TRAMI registries. JACC Cardiovasc Interv. 2020;13:543-50.

21. Rommel KP, Besler C, Noack T, et al. Physiological and clinical consequences of right ventricular volume overload reduction after transcatheter treatment for tricuspid regurgitation. JACC Cardiovasc Interv. 2019;12:1423-34. 